(2) Open Access Full Text Article

\title{
Apparent histological changes of adipocytes after treatment with CL 316,243, a $\beta$-3-adrenergic receptor agonist
}

\author{
Masoud Ghorbani ${ }^{1,2, *}$ \\ Shahram Teimourian ${ }^{3, *}$ \\ Reza Farzad ${ }^{4}$ \\ Nabiollah Namvar As/ ${ }^{4}$ \\ 'Research and Development \\ Department, Pasteur Institute \\ of Iran, Tehran, Iran; ${ }^{2}$ Department \\ of Biochemistry, University of Ottawa, \\ Ottawa, ON, Canada; ${ }^{3}$ Department \\ of Medical Genetics, Iran University \\ of Medical Sciences, Tehran, Iran; \\ ${ }^{4}$ Department of Animal Science, \\ Pasteur Institute of Iran, Research \\ and Production Complex, Karaj, Iran \\ *These authors contributed equally \\ to this work
}

This article was published in the following Dove Press journal:

Drug Design, Development and Therapy

II February 2015

Number of times this article has been viewed

Background and objectives: The objective of this experiment was to study the effect of CL 316,243 (CL) (a highly selective $\beta 3$-adrenergic receptor agonist) on cellular changes occurring in retroperitoneal white adipose tissue (RWAT) of lean and obese rats.

Methods: Ten-month-old lean and obese Zucker rats were implanted subcutaneously with osmotic mini-pumps, infusing either saline or CL ( $1 \mathrm{mg} / \mathrm{kg}$ body weight/day) for 4 weeks.

Results: There was no effect of CL on food intake. However, the resting metabolic rate in lean and obese rats increased by $55 \%$ and $96 \%$ per rat, respectively. Total RWAT weight decreased in both lean and obese rats under influence of CL treatment by $65 \%$ and $38 \%$, respectively. Total body weight and body fat were lower in CL treated rats. Detection of uncoupling protein 1 (UCP1) in RWAT was confirmed qualitatively by both immunohistochemistry and immunofluorescence using a rabbit anti rat UCP1 antibody which showed the appearance of a marked increase of this protein in the adipose tissue. Stained semi-thin sections $(0.5 \mu \mathrm{m})$ also demonstrated abundant nuclei in multilocular adipocytes, in endothelial cells associated with the vasculature, and in interstitial cells. In CL-treated obese rats, a clustering of several multilocular cells around the periphery of a white adipocyte was seen.

Conclusion: These results indicate that treatment of both lean and obese Zucker rats with CL induces extensive remodeling of RWAT that includes shrinkage of white adipose tissue, appearance of abundant multilocular cells in RWAT together with the appearance of a marked increase of UCP, preferentially in lean rats.

Keywords: brown adipose tissue, cellularity of adipose tissue, obesity, thermogenesis, uncoupling protein, Zucker rats

\section{Introduction}

$\beta$-adrenergic receptors have been classified as $\beta 1$ and $\beta 2$ since $1967 .{ }^{1}$ Rat adipocyte lipolysis was initially thought to be a $\beta 1$-mediated process. However, recent evidence shows that the receptor mediating lipolysis is neither $\beta 1$ nor $\beta 2$, but atypical in nature. ${ }^{2}$ These atypical receptors, now called $\beta 3$-adrenoceptors, are found on the cell surface of both white and brown adipocytes where their stimulation promotes both lipolysis and energy expenditure in brown adipose tissue (BAT) and lipolysis in white adipose tissue (WAT). ${ }^{3}$ The thermogenesis function in BAT largely depends on an integral membrane protein located at the inner membrane of mitochondria that is called thermogenin or uncoupling protein one (UCP1). ${ }^{4,5}$ UCP1 is responsible for translocation of protons into the mitochondria and elevation of respiration rate without an increase in ATP synthesis which in turn induces energy dissipation as heat. ${ }^{6}$ It has been reported that a chronic administration of the $\beta 3$-adrenergic agonists can induce

Correspondence: Masoud Ghorbani Pasteur Institute of Iran, Research and Development Department, Kilometer 25 Karaj-Tehran Highway, 31599,

Tehran, Iran

Tel +982616102999

Fax +982616102900

Email mghorbani@irimc.org 
the ectopic expression of UCP in white fat and skeletal muscle. $\beta 3$-adrenergic agonists can induce a functionally active UCP in fat and slow-twitch muscle fibers in rodents and humans ${ }^{7}$ except guinea pigs which lack $\beta 3$-adrenergic receptors in their fat tissue. ${ }^{8}$

Development of thermogenic drugs for treatment of obesity has now focused on selective $\beta 3$-adrenergic agonists. It has been postulated that thermogenic drugs might stimulate thermogenesis in BAT and induce lipolysis of WAT. ${ }^{4}$ In a previous study we demonstrated that the daily treatment of rats with CL 316,243 (CL), a highly selective $\beta 3$-adrenergic agonist, ${ }^{9}$ for 4 weeks reversed the development of obesity induced by a high fat diet. ${ }^{10}$ This reversal of obesity was associated with an increase in metabolic rate (without any change in food intake) and an augmentation in mitochondrial proliferation, including an increase in the level of UCP in BAT. It was later discovered that there were several UCPs which are tissue specific and the one which is specific for adipose tissue was named UCP1. In the present work, we describe the effects of CL on energy balance, lipolysis, and cell type differentiation in WAT as well as in type II diabetes in lean and obese Zucker rats. In addition, we document with both immunohistochemistry and immunofluorescence changes in the occurrence of UCP1 in WAT.

\section{Material and methods}

\section{Chemicals}

CL (disodium(R, R)-5-)2-[[2-3-(3-chlorophenyl)-2-hydroxyethyl]-amino] propyl-1, 3-benzodioxole-2, 2-dicarboxylate (Figure 1) was a gift from American Cyanamid Company, Pearl River, New York, USA (Bloom et al 1992). ${ }^{2}$ All other chemicals were purchased from Sigma-Aldrich Co. (St Louis, MO, USA).

\section{Study design}

All animal protocols were reviewed and approved by Pasteur Institute of Iran Animal Care and Use Committee. The study was performed over a period of 12 months between April 2012 and April 2013. All biochemical and

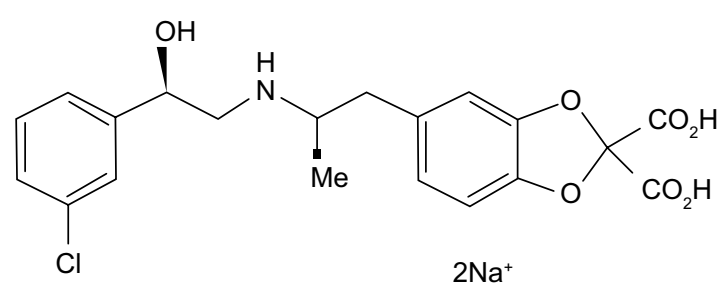

Figure I Structure of CL 316,243. histological assays where performed at both University of Ottawa and Pasteur Institute of Iran laboratories. Thirty obese $\mathrm{fa} / \mathrm{fa}$ Zucker rats and 30 lean littermates were purchased at 11 weeks of age from Charles River Canada and housed at $24^{\circ} \mathrm{C}$ in plastic cages containing wood chips with free access to food (with $14.5 \%$ energy from fat) and water. After animals reached 36 weeks of age, at which time WAT shows a large increase in number of mature white adipocytes, ${ }^{11,12}$ food intake and body weight were measured weekly for 4 weeks. Each group of rats was separated into three groups of ten animals. One group of ten, from both obese and lean Zucker rats, was killed immediately after separation (week 0, lean 4 and fatty 4 ). The rest of the rats were implanted subcutaneously with mini-osmotic pumps (Alzet 2002; Alzet, Palo Alto, CA, USA) perfusing $0.5 \mu \mathrm{L}$ /hour of either saline or CL ( $1 \mathrm{mg} / \mathrm{kg}$ body weight/day) for 2 weeks. Rats in all groups were then killed and retroperitoneal white adipose tissue (RWAT) was dissected. A small amount of tissue was placed in buffered formalin for both immunohistochemistry and immunofluorescence and the remainder of the tissue was kept on ice until it was homogenized and stored at $-80^{\circ} \mathrm{C}$ for further assays. Some samples of RWAT were fixed in buffered glutaraldehyde solution ( $2 \%$ paraformaldehyde and $2.5 \%$ glutaraldehyde) and after embedding in Epon, semithin sections $(0.5 \mu \mathrm{m})$ were cut and stained with methylene blue and azur II. ${ }^{13}$ We also took samples for measurement of cellularity, using Hirsch and Gallian's method ${ }^{14}$ which measures the number of mature white adipocytes.

\section{Assays}

Frozen tissue samples were homogenized in isolation medium [0.25 M sucrose, $0.2 \mathrm{mM}$ dipotassium ethylenediaminetetraacetic acid (EDTA), and 1.0 mM (4-(2-hydroxyethyl)-1-piperazineethanesulfonic acid) (HEPES), in distilled water, $\mathrm{pH} 7.2] .{ }^{8}$ Proteins were measured by a modified Lowry et al method as before. ${ }^{8,10}$ DNA was measured in delipidated WAT homogenate with dye binding (Hoechst 33258) (Sigma-Aldrich Co.) fluorometric method and UCP1 in WAT was assessed by sodium dodecyl sulphate-polyacrylamide gel electrophoresis (SDS-PAGE) followed by Western blotting.

\section{Energy expenditure}

On day 12 after implantation, resting metabolic rate was measured using an oxygen analyzer (Beckman Industrial Oxygen Analyzer Model 755). Each rat was placed in a temperature controlled chamber at $24^{\circ} \mathrm{C}$ and airflow was regulated with a Brooks thermal mass flow meter (Brook Instrument Division, Emerson Electric, Hatfield, PA, USA). 
Oxygen concentration in the air flowing through the chamber was calculated using a computer program. ${ }^{15}$

\section{Tissue fixation}

Rats were killed by decapitation and RWAT was removed and fixed in $10 \%$ buffered formalin. After embedding the tissue in paraffin, thick sections ( 7 to $10 \mu \mathrm{m}$ ) were cut, deparaffinized and rehydration of the sections took placed as follows: sections rehydrated by immersion in xylene (twice for 5 minutes), $100 \%$ ethanol (twice for 3 minutes), 95\% ethanol (once for 3 minutes), $70 \%$ ethanol (once for 3 minutes), and water (once for 5 minutes). Sections were then stained with hematoxylin and eosin (6 minutes incubation in filtered Delafield's hematoxylin, rinsed in water, and immersed in alcohol [30\% alcohol $+1 \% \mathrm{HCL}$ ] for 3 seconds, washed in $1 \%$ lithium carbonate in water until the section was blue, washed in running water for 10 minutes, placed in eosin for 2 minutes, dehydrated through 95\% alcohol [2 minutes], 100\% alcohol [2 minutes, twice], and xylol [2 minutes], and mounted in permount).

\section{Immunohistochemistry}

Deparaffinization and rehydration of sections were exactly the same as mentioned above. Antibody against rat UCP1 was raised in rabbits and the sera was stored in glycerol 1:1 at $-20^{\circ} \mathrm{C}$. Sections were incubated with the primary antibody to rat UCP1 diluted with TCT (1:100) (tris- $\mathrm{HCl}$ pH 8, 0.6\% carrageenan and $0.3 \%$ Triton $\mathrm{X}-100$ ) overnight at $4{ }^{\circ} \mathrm{C}$. The next day, sections were washed twice in TBS buffer $(0.1$ $\mathrm{M}$ Tris and $0.14 \mathrm{M}$ sodium chloride) for 7 minutes and incubated with a secondary antibody (donkey anti-rabbit immunoglobulin, biotinylated whole antibody) (Abcam, Cat\#ab6801) diluted in TCT buffer (1:50) for 30 minutes. Sections were washed in TBS twice for 7 minutes and neutralized in 3\% hydrogen peroxide diluted with TBS for 10 minutes. Sections were washed again in TBS for 7 minutes and were then incubated with streptavidin-horseradish peroxidase conjugate diluted with TCT (1:50) for $30 \mathrm{~min}$ utes at room temperature (RT). They were washed in TBS twice for 7 minutes, then incubated with diaminobenzidine (Sigma-Aldrich Co.) $(200 \mu \mathrm{g} / 100 \mathrm{~mL}$ TBS $+700 \mu \mathrm{L} \mathrm{10 \%}$ nickel chloride $+10 \mu \mathrm{L}$ hydrogen peroxide) for 12 minutes in the dark. Sections were then dehydrated in alcohol, cleared in xylol, and mounted in permount.

\section{Immunofluorescence}

After deparaffinization and rehydration, sections were rinsed in phosphate buffered saline (PBS) for 2 minutes, and were then incubated with primary antibody to UCP1 for 40 minutes at RT. They were then washed three times and incubated with secondary antibody, biotinylated donkey anti rabbit immunoglobulin G (Abcam, Cat\#ab6801), (1:100) for 30 minutes at RT. Slides were washed three times and incubated with streptavidin fluorescein isothiocyanate (FITC) conjugate (eBioscience, Cat\#11-4317) (1:30) for 40 minutes. They were rinsed again in PBS and incubated with propidium iodide (Biolegend, Cat\# 421301) (1:3,000) for 2 minutes. Finally, they were rinsed in PBS and mounted.

\section{Measurement of blood glucose, serum insulin and fatty acids (FAs)}

Serum insulin was measured by enzyme-linked immunosorbent assay (ELISA) (Ultra Sensitive Rat Insulin kit, Morinaga Institute of Biological Science, Inc, Yokohama, Japan). Serum glucose was measured by a hexokinase/glucose-6phosphate dehydrogenase method on a Coulter DACOS device (510 k Decisions, Irvine, CA, USA). Homeostasis model assessment was calculated as the product of fasting insulin (micro units per milliliter) and fasting glucose (micromoles per liter) divided by 22.5. ${ }^{16}$ Fasting serum insulin and homeostasis model assessment were used as markers of insulin resistance. ${ }^{17}$ Serum FAs were measured using an FAs assay kit (Hoffman-La Roche Ltd., Basel, Switzerland).

\section{Statistical analysis}

Results are presented as means \pm standard error of the mean (SEM). Statistical analysis used Instat software to do analysis of variance (ANOVA) followed by a Student Newman-Keuls test. Significant differences are based on $P<0.05$.

\section{Results}

Four weeks' treatment of rats with CL did not alter significantly the final body weight of lean rats; however the body weight of obese Zucker rats treated with CL was slightly lower than control rats (Figure 2). There was no difference

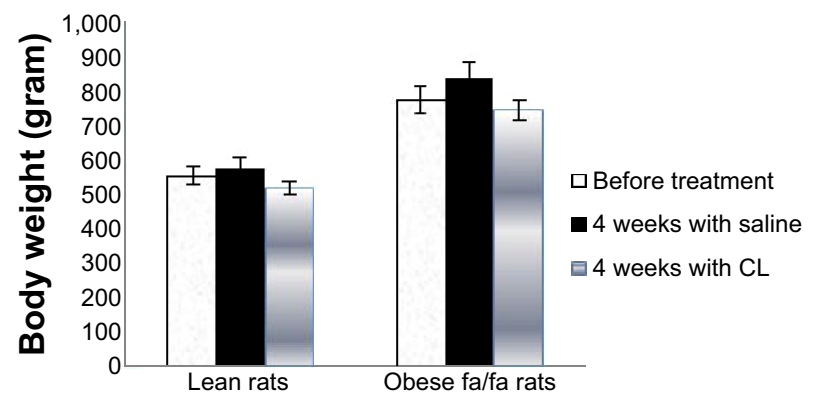

Figure 2 Body weight in CL-treated or control lean or obese fa/fa rats. Notes: Bars are mean \pm SEM for ten rats. No significant differences were observed. Abbreviations: $C L, C L 316,243$; SEM, standard error of the mean. 


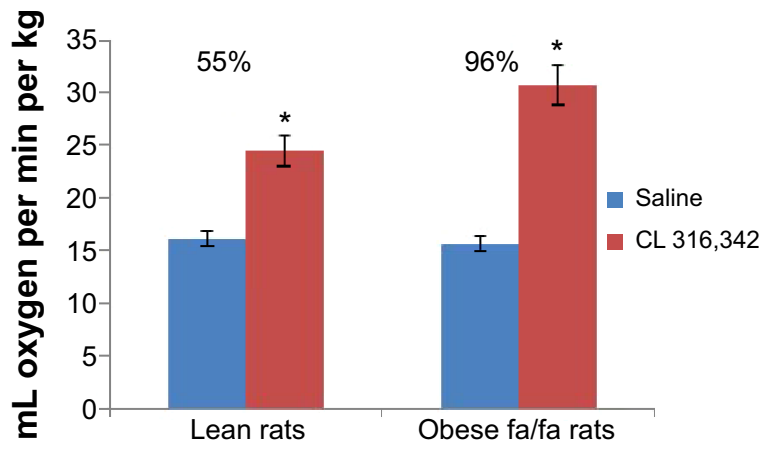

Figure 3 Effect on metabolic rate in CL-treated or saline-treated lean or obese Zucker rats after 4 weeks treatment.

Notes: Bars are mean \pm SEM for four rats. *Significant values are based on $P<0.05$ Abbreviations: CL, CL 316,243; SEM, standard error of the mean; min, minute.

in food intake in drug treated and untreated rats in both lean and obese rats (data not shown).

The resting metabolic rates of rats treated with CL were increased by $96 \%$ in obese and $55 \%$ in lean rats based on their kilogram body weight, while there was no marked increase in their body temperature $\left(37.3^{\circ} \mathrm{C}\right.$ to $\left.38.2^{\circ} \mathrm{C}\right)$ as compared to control rats (Figure 3).

RWAT weight was much greater in untreated obese $\mathrm{fa} / \mathrm{fa}$ rats after 4 weeks feeding, however in CL-treated rats, it significantly decreased in both lean and obese rats (Figure 4).

Protein content of RWAT was substantially increased by the CL-treatment in both lean and fa/fa rats (Figure 5). In previous experiments we have shown that the treatment of rats with CL stimulated thermogenesis in BAT by increasing the number of mitochondria and the amount of cytochrome oxidase and UCP in this tissue which is associated with a marked decrease of DNA concentration in WAT. ${ }^{18}$

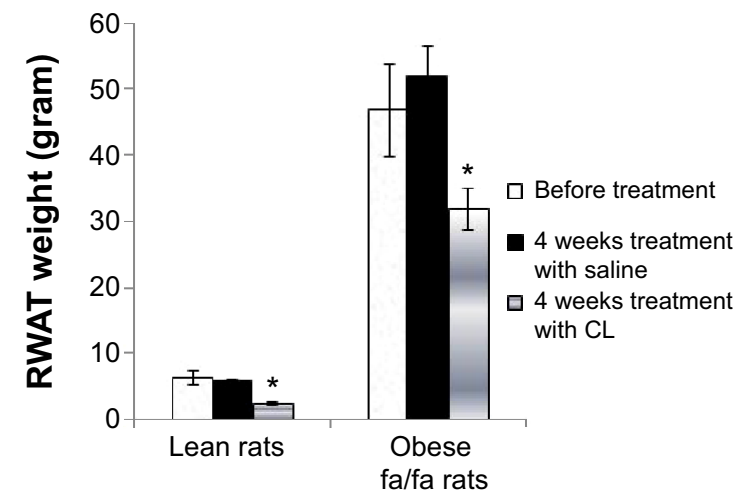

Figure 4 Effect of CL on RWAT weight in lean and obese rats.

Notes: Bars are mean \pm SEM for four rats. *Significant values are based on $P<0.05$. Abbreviations: CL, CL 316,243; SEM, standard error of the mean; RWAT, retroperitoneal white adipose tissue.

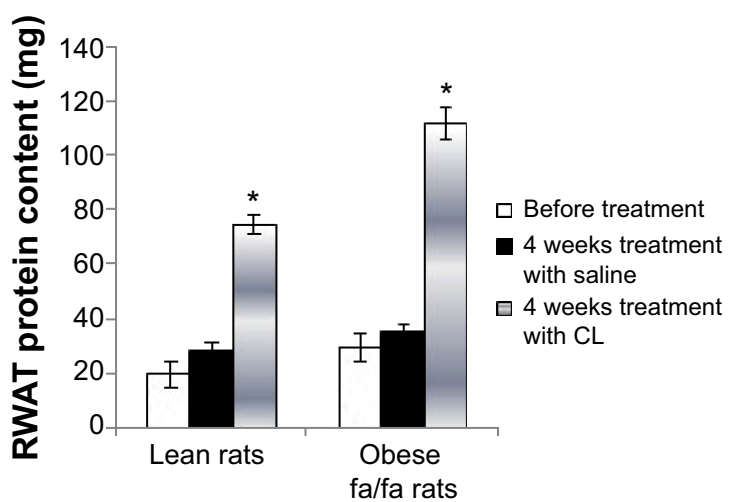

Figure 5 Protein contents of RWAT.

Notes: CL-treatment increased total protein in both lean and obese fa/fa rats significantly $(* P<0.001)$.

Abbreviations: CL, CL 316,243; RWAT, retroperitoneal white adipose tissue.

In this paper we report the specific effect of $\mathrm{CL}$ on WAT morphology and its relevance to type 2 diabetes. To investigate whether CL-treatment induces any changes of cell types in WAT, tissues were processed to assess the presence of multilocular cells and UCP in WAT. Blood samples were also assayed for differences in serum insulin, blood glucose, and free acids levels in treated and untreated rats.

Staining of WAT sections with hematoxylin and eosin showed the appearance of multilocular fat cells among white adipocytes (Figure 6). To establish the brown fat cell character for these cells, we used immunohistochemistry to show that these multilocular cells contained UCP1, not visible at all in RWAT of the saline-treated rats (Figure 7). Higher power light microscopy of semi-thin sections showed the multilocular cells to have darkly stained cytoplasm, numerous small lipid droplets, and large pale nuclei with a prominent nucleoli, characteristic of brown adipocytes (Figure 8). To demonstrate the presence of brown adipocytes containing UCP in WAT of CL-treated rats we used confocal microscopy technique using a LEICA confocal laser scanning microscope (Leica Microsystems, Wetzlar, Germany). For this purpose we used $10 \mu \mathrm{m}$ paraffin sections labeled with antibody to rat UCP1 and conjugated with FITC. Confocal micrographs showed appearance of abundant multilocular cells with numerous small lipid droplets in CL-treated lean rats (Figure 9). Western blotting showed that RWAT of CL-treated rats contained a $32 \mathrm{kd}$ protein, identified as UCP1, more abundant in lean rats than $\mathrm{fa} /$ fa rats (data not shown).

Treatment with CL also decreased the serum insulin level in fa/fa rats. In oral glucose tolerance test, serum insulin and blood glucose levels were significantly higher in the obese rats treated with saline after feeding with $2 \mathrm{mg}$ glucose $/ \mathrm{g}$ 

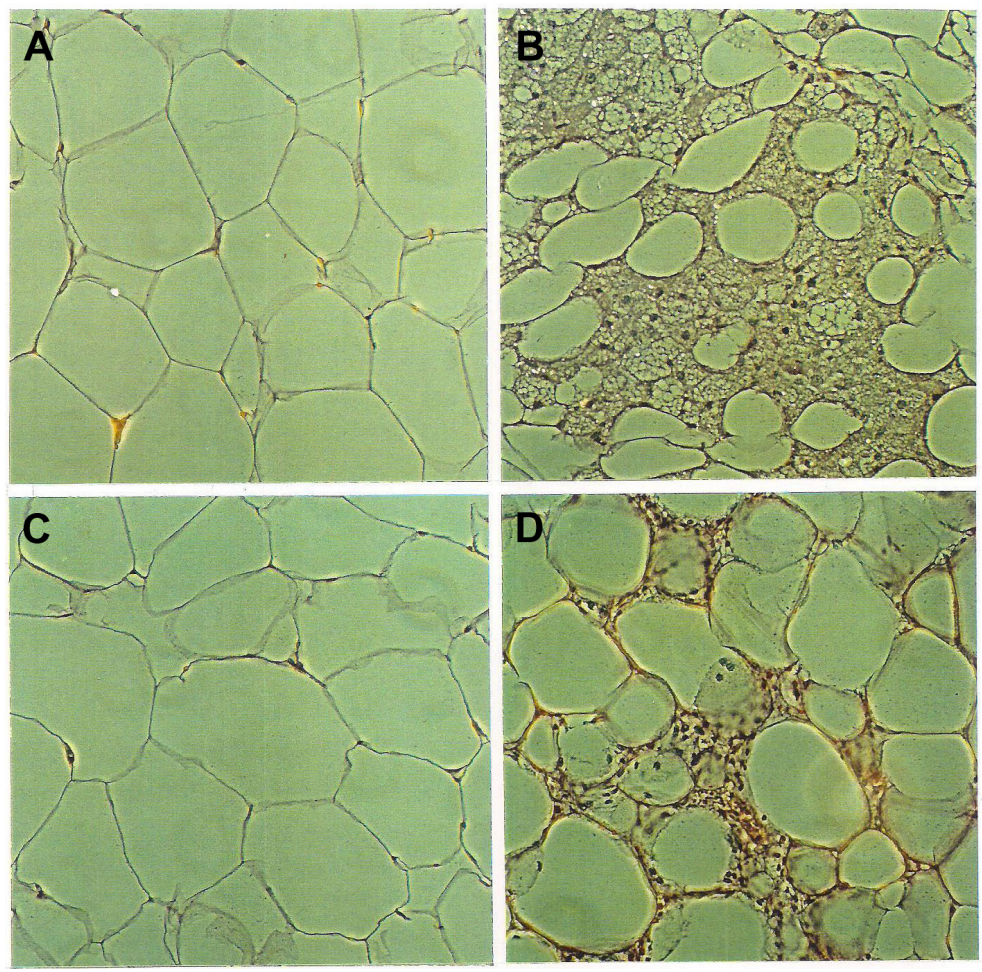

Figure 6 Light micrographs of the appearance of multilocular adipocytes.

Notes: Light micrographs of the appearance of multilocular adipocytes in $10 \mu \mathrm{m}$ sections of RWAT in lean and fatty Zucker rats. (A) control lean rat (B) CL-treated lean rat (C) control fatty rat (D) CL-treated fatty Zucker rat. Sections were stained with hematoxylin and eosin. Abundant multilocular cells appeared in RWAT of CL-treated rats. Bars $20 \mu \mathrm{m}$. Magnification is $\times 400$.

Abbreviations: CL, CL 316,243; RWAT, retroperitoneal white adipose tissue.
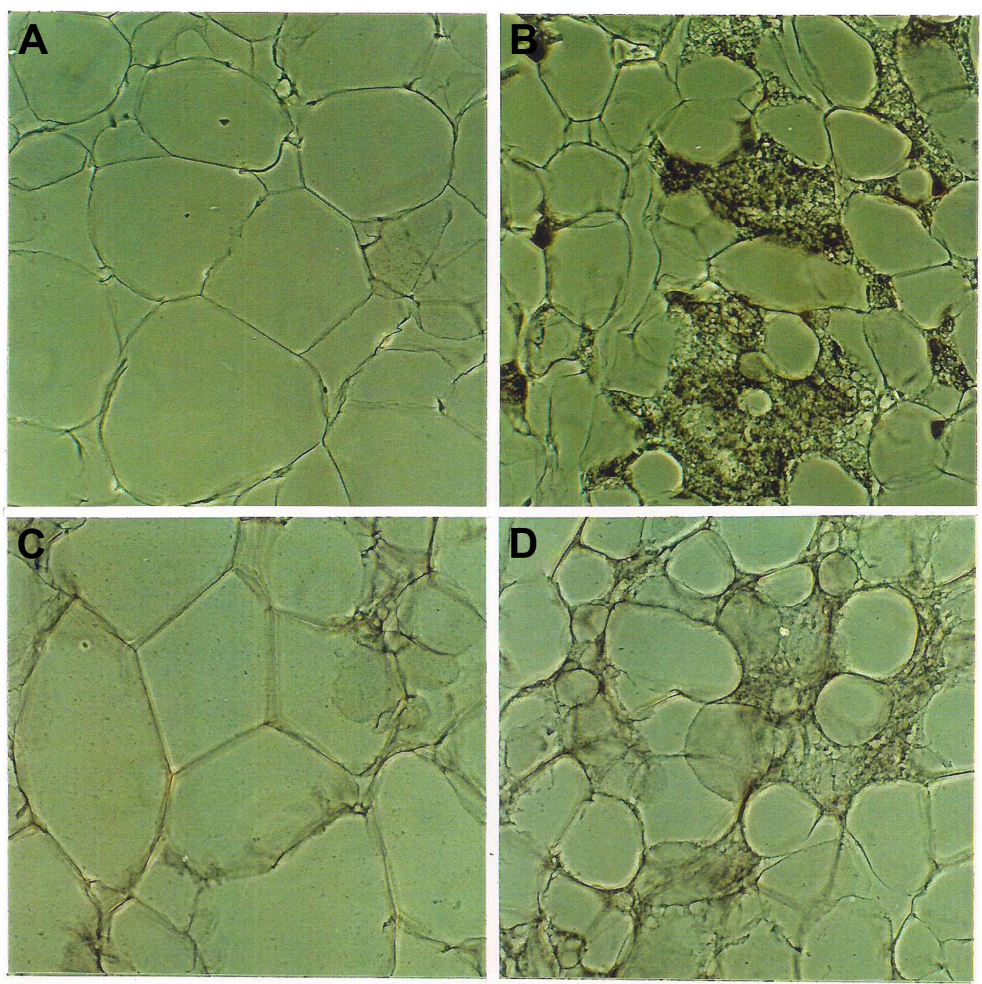

Figure 7 Immunochemical detection of UCP in RWAT.

Notes: Sections $(10 \mu \mathrm{m})$ were immunolabeled with an antibody specific to UCP. The black spots are immunoreactive UCP in WAT of both lean and fa/fa rats under CLtreatment. (A) Control lean rat; (B) CL-treated lean rats; (C) control fa/fa rat; (D) CL-treated fa/fa rat. Bars $20 \mu \mathrm{m}$. Magnification is $\times 400$.

Abbreviations: CL, CL 316,243; RWAT, retroperitoneal white adipose tissue; UCP, uncoupling protein; WAT, white adipose tissue. 

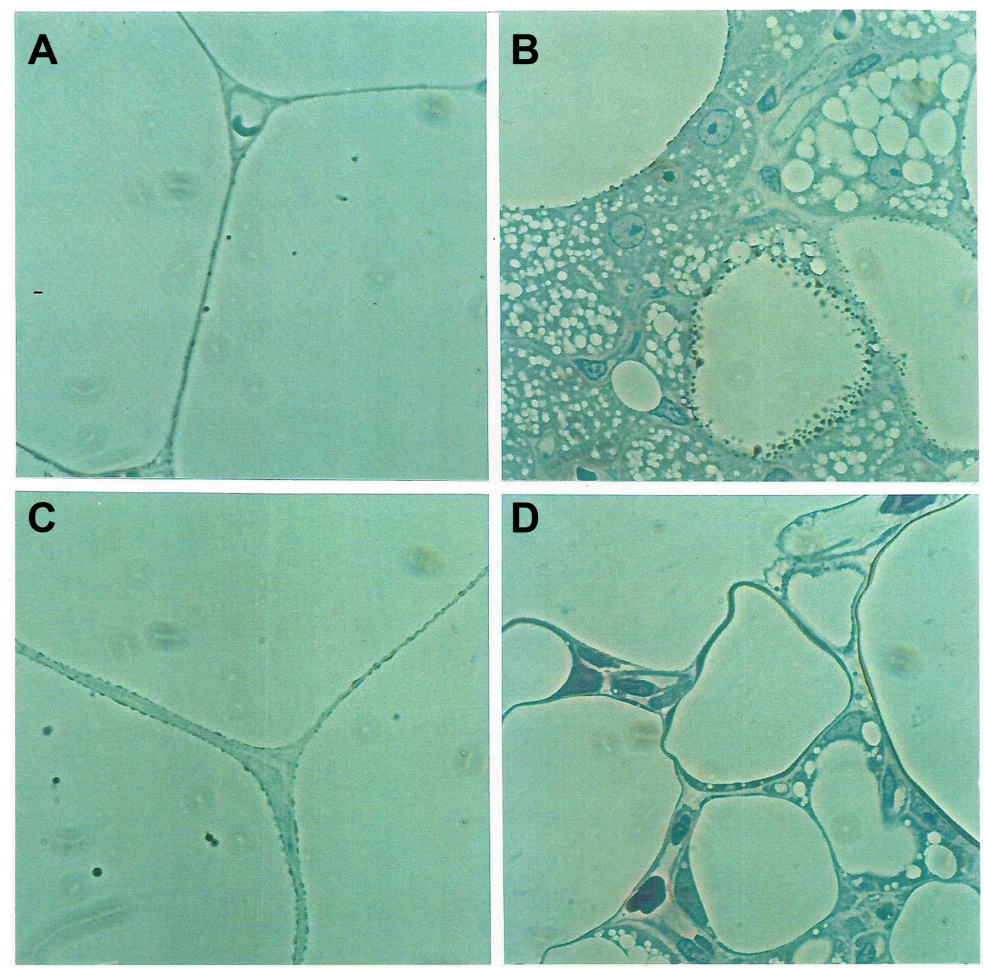

Figure 8 Higher power light microscopy of semi-thin sections of RWAT.

Notes: Semi-thin sections $(0.5 \mu \mathrm{m})$ were cut and stained with methylene blue and azur II. Prints show the multilocular cells with darkly-stained cytoplasm, numerous small lipid droplets and large pale nuclei. (A) Control lean rat; (B) CL-treated lean rat; (C) control fa/fa rat; (D) CL-treated fa/fa rat. Bars $10 \mu \mathrm{m}$. Magnification $\times 2,000$. Abbreviations: CL, CL 316,243; RWAT, retroperitoneal white adipose tissue.
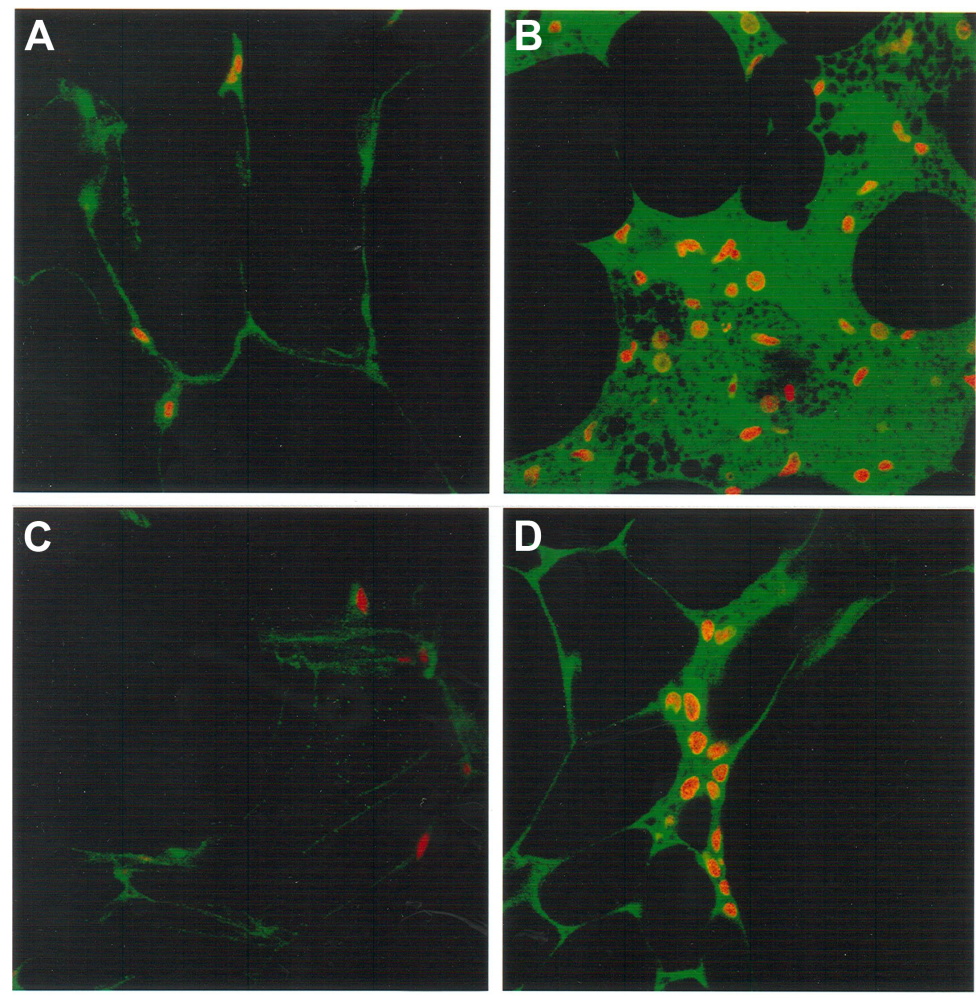

Figure 9 Confocal micrographs of RWAT of lean rat treated with CL 316,243 (CL).

Notes: Appearance of multilocular cells with numerous small lipid droplets (shown in black) and abundant immunolabeled UCP stained with FITC (green areas) in CL-treated lean rat. (A) RWAT of control lean rat; (B) RWAT of CL-treated lean rat; (C) side view of RWAT of control fa/fa rat; (D) side view of RWAT of CL-treated fa/fa rat. Bars $20 \mu \mathrm{m}$. Magnification is $\times 500$.

Abbreviations: RWAT, retroperitoneal white adipose tissue; UCP, uncoupling protein; FITC, fluorescein isothiocyanate. 
A

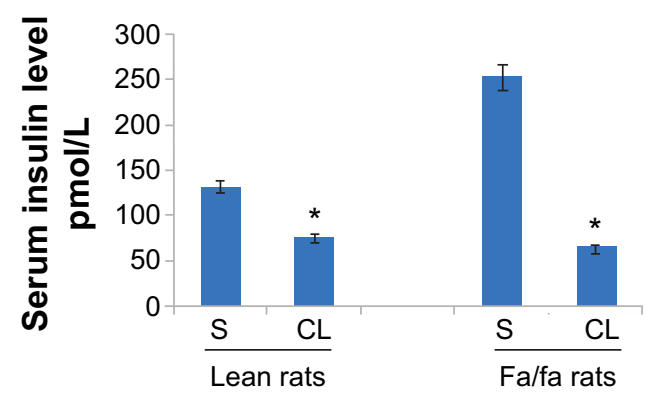

B

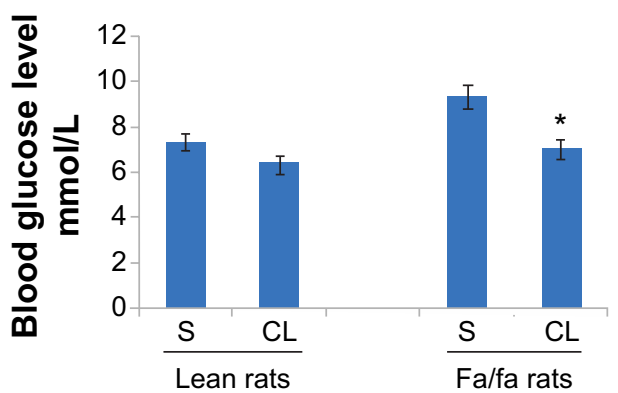

Figure 10 (A) Serum insulin and (B) blood glucose levels in both control and CL 316,243 treated rats.

Notes: Bars are mean \pm SEM for ten rats. *Significant values are based on $P<0.05$.

Abbreviations: CL, CL 316,243; SEM, standard error of the mean; S, saline.

body weight as compared with lean rats treated with saline. Treatment with CL significantly decreased both serum insulin and blood glucose levels in fa/fa rats (Figure 10A and B). Measurement of serum FAs also showed a marked decrease in obese rats treated with CL which was accompanied by normoglycemia and improvement of insulin resistance indicating that $\beta 3$-adrenergic responsiveness is present in these rats (Figure 11).

\section{Discussion}

The present study examined the effect of CL on cellular changes in RWAT for lean and obese Zucker rats. In this experiment the stimulatory effects of CL compound on thermogenesis and adipocyte lipolysis were determined through biochemical assays, measurement of food intake, and resting metabolic rate. The results indicate that $\mathrm{CL}$, a highly selective $\beta 3$-adrenoceptor agonist, ${ }^{2,8}$ has anti-obesity effects on lean and obese rats without changing food intake. The effect of $\mathrm{CL}$ was associated with an increase in thermogenesis shown by an increased resting metabolic rate $(66 \%$ in obese rats versus $39 \%$ in lean rats [Figure 3]), which eventually promotes leanness. An increase in energy expenditure induced by a

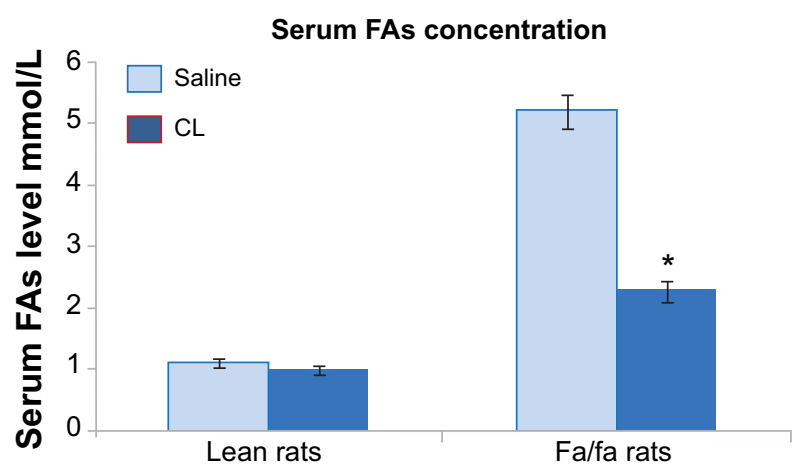

Figure I I Serum fatty acids level in lean and obese rats treated with CL 316,243. Notes: Bars are mean \pm SEM for ten rats. *Significant values are based on $P<0.05$. Abbreviations: $C L, C L$ 316,243; SEM, standard error of the mean; FAs, fatty acids. $\beta 3$-adrenoceptor agonist is likely to be occurring in brown adipocytes.

Treatment with CL induced a remarkable atrophy of retroperitoneal fat depots in obese rats. However, lean rats did not show such a decrease of fat depots in their RWAT which could be due to the very low level of fat depots in these rats. Morphological studies showed that white adipocyte size in CL-treated rats was smaller than in control, and even less than in lean animals (data not shown). These data demonstrate that under the influence of CL, fat cells lose their lipid content and become smaller, while the number of mature fat cells remains constant. A marked decrease in DNA content of RWAT (Figure 5) also shows that CL-treatment results in considerable apoptosis.

One of the most important differences between white and brown adipocytes is the presence of UCP in the latter. ${ }^{19,20}$ Thus, the presence of UCP in the white fat deposit of the CL-treated rats could be due to the transformation of white adipocytes into brown adipocytes, or to recruitment of dormant brown fat cells present in the white fat deposit. However the appearance of multilocular cells and UCP1 in WAT of obese rats was much lower than that in lean rats (Figures 6-8). That could be due to the existence of a lower number of precursor cells in obese animals since most fat cells in these rats are mature adipocytes. ${ }^{21,22}$

In this study we have also demonstrated the correlation of $\beta$-adrenergic receptor stimulation and the improvement of serum insulin and blood glucose level in obese fa/fa rats. It has also been documented that the improvement of NIDDM in these animals by treatment with CL is linked with the suppression of TNF- $\alpha$ messenger ribonucleic acid expression in WAT. ${ }^{16}$

This study showed that the hyperplasticity characterized by an increased number of mature white adipocytes as well as insulin-resistance condition in genetically obese fa/fa rats can be improved by treatment with CL. The finding of an 
increased amount of UCP1 in WAT could stimulate further investigation into the activation of thermogenesis in WAT through the synthesis of UCP1 in this tissue.

\section{Disclosure}

The authors have no conflicts of interest to disclose.

\section{References}

1. Lands AM, Arnold A, McAuliff JP, Luduena FP, Brown TG Jr. Differentiation of receptor systems activated by sympathomimetic amines. Nature. 1967;214(5088):597-598.

2. Bloom JD, Dutia MD, Johnson BD, et al. Disodium (R,R)-5-[2-[[2-(3chlorophenyl)-2-hydroxyethyl]-amino] propyl]-1,3-benzodioxole-2,2dicarboxylate (CL 16,243). A potent beta-adrenergic agonist virtually specific for beta 3 receptors. A promising antidiabetic and antiobesity agent. J Med Chem. 1992;35(16):3081-3084.

3. Arch JR, Kaumann AJ. Beta 3 and atypical beta-adrenoceptors. Med Res Rev. 1993;13(6):663-729.

4. Himms-Hagen J. Brown adipose tissue thermogenesis and obesity. Prog Lipid Res. 1989;28(2):67-115.

5. Nicholls DG, Locke RM. Thermogenic mechanisms in brown fat. Physiol Rev. 1984;64(1):1-64.

6. Rousset S, Alves-Guerra MC, Mozo J, et al. The biology of mitochondrial uncoupling proteins. Diabetes. 2004;53 Suppl 1:S130-S135.

7. Yoshida T, Umekawa T, Kumamoto K, et al. Beta 3-Adrenergic agonist induces a functionally active uncoupling protein in fat and slow-twitch muscle fibers. Am J Physiol. 1998;274(3 Pt 1):E469-E475.

8. Himms-Hagen J, Triandafillou J, Begin-Heick N, Ghorbani M, Kates AL. Apparent lack of beta 3-adrenoceptors and of insulin regulation of glucose transport in brown adipose tissue of guinea pigs. American Journal of Physiology-Regulatory, Integrative and Comparative Physiology. 1995;268(1):R98-R104.

9. Dolan JA, Muenkel HA, Burns MG, et al. Beta-3 adrenoceptor selectivity of the dioxolane dicarboxylate phenethanolamines. J Pharmacol Exp Ther. 1994;269(3):1000-1006.

10. Ghorbani M, Claus TH, Himms-Hagen J. Hypertrophy of Brown Adipocites in Brown and White Adipose Tissue and Reversal of DietInduced Obesity in Rats Treated with a $\beta 3$-Adrenoceptor Agonist. Biochem Pharmacol. 1997;54(1):121-131.
11. Bray GA. Commentary on classics in obesity. 5. Fat cell theory and units of knowledge. Obes Res. 1993;1(5):403-407.

12. Phillips FC, Cleary MP. Metabolic measurements among homozygous $(\mathrm{fa} / \mathrm{fa})$ obese, heterozygous $(\mathrm{Fa} / \mathrm{fa})$ lean and homozygous $(\mathrm{Fa} / \mathrm{Fa})$ lean Zucker rat pups at 17 days of age. J Nutr. 1994;124(8):1230-7123.

13. Géloën A, Collet AJ, Bukowiecki LJ. Role of sympathetic innervation in brown adipocyte proliferation. Am J Physiol. 1992;263(6 Pt 2): R1176-R1181.

14. Hirsch J, Gallian E. Methods for the determination of adipose cell size in man and animals. J Lipid Res. 1968;9(1):110-119.

15. Ma SW, Foster DO. Uptake of glucose and release of fatty acids and glycerol by rat brown adipose tissue in vivo. Can J Physiol Pharmacol. 1986;64(5):609-614.

16. Ghorbani M, Shafiee Ardestani M, Hatami Gigloo S, Ahangari Cohan R, Nouri Inanlou D, Ghorban P. Anti Diabetic effect of CL 316,243 (A 33 -Adrenergic Agonist) By Down Regulation of Tumour Necrosis Factor (TNF- $\alpha$ ) Expression. Plos One. 2012;7(10):e45874.

17. No JI, Yang JY, Hyun HJ, Yeon CS, Choi HJ. Factors Associated with Serum Levels of Carcinoembryonic Antigen in Healthy Non-smokers. Korean J Fam Med. 2013;34(6):413-419.

18. Ghorbani M, Himms-Hagen J. Appearance of brown adipocytes in white adipose tissue during CL 316,243-induced reversal of obesity and diabetes in Zucker fa/fa rats. Int J Obes Relat Metab Disord. 1997; 21(6):465-475.

19. Sanchez-Gurmaches J, Guertin DA. Adipocyte lineages: Tracing back the origins of fat. Biochim Biophys Acta. 2013;1842(3):340-351.

20. Macotela Y, Emanuelli B, Mori MA, et al. Intrinsic differences in adipocyte precursor cells from different white fat depots. Diabetes. 2012; 61(7):1691-1699.

21. Milam KM, Keesey RE, Storlien LH, Stern JS. Developmental study of adipose cellularity in lateral hypothalamic-lesioned Zucker obese rats. Am J Physiol. 1982;242(3):R311-R317.

22. Cousin B, Cinti S, Morroni M, et al. Occurrence of brown adipocytes in rat white adipose tissue: molecular and morphological characterization. J Cell Sci. 1992;103(Pt 4):931-942.
Drug Design, Development and Therapy

\section{Publish your work in this journal}

Drug Design, Development and Therapy is an international, peerreviewed open-access journal that spans the spectrum of drug design and development through to clinical applications. Clinical outcomes, patient safety, and programs for the development and effective, safe, and sustained use of medicines are a feature of the journal, which

\section{Dovepress}

has also been accepted for indexing on PubMed Central. The manuscript management system is completely online and includes a very quick and fair peer-review system, which is all easy to use. Visit http://www.dovepress.com/testimonials.php to read real quotes from published authors. 